\title{
FiVe MORE STEPS AND YOU WILL BE A NEW PERSON: THE PROCEDURAL CLOSURE OF THE EXPERIENTIAL FIELD IN EVERY DAY THE SAME Dream
}

\author{
Christophe Duret
}

\begin{abstract}
This paper will provide an analysis of the editorial game Every Day the Same Dream $(E D S D)$. EDSD assumes the specific characteristics of a thesis novel (a "thesis game", in this specific case) which Suleiman (1983:1) defined as a type of novel which explicitly puts forth "recognized body of doctrine or system of ideas" and which has an "unambiguous dualistic system of values [...] rules of action addressed to the reader [and a] doctrinal intertext" (Suleiman, 1983: 54). According to the principle of procedural rhetoric (Bogost, 2008), the thesis of EDSD is mainly defended through the formal structure of the game, especially in the problem solving processes performed by the player. We therefore analyze EDSD as a thesis game by putting forward the concept of "micro-apparatus of procedural closure of the experiential field", which arises from the meeting of hermeneutic and cognitive sciences, the objective being to describe the strategies used to disseminate a persuasive message among players and to analyze its reception.
\end{abstract}

KEYWORDS

Editorial game; procedural closure, micro-apparatus, procedural rhetoric, thesis game

\section{INTRODUCTION $^{1}$}

According to Brougère (2002: 14), the particularity of the game, is its "second level, or in other words, the recovery of meaning from the context of daily life or of the first level that gives them a new meaning in the fictional context, in the broadest sense". The second level adds a distance, an ability to analyze the reality to which the game refers. Trémel (2002) concurs. Interested in tabletop role-playing games, he notes how the genre of "cyberpunk", by staging futuristic dystopias, fosters social critique among the players through the parallels they draw between this world and modern reality. Such games "provide an opportunity for players to develop a critical culture that serves to analyze their daily lives - and more generally the functioning of modern societies" (Trémel, 2002: 52).

The development of a critical reading of society and of daily life as highlighted by Trémel reflects the power of revelation of video games when taken as texts, of selfreflection by the player and of the contemporary world, and that this reflection has been prompted voluntarily or otherwise by their designers and effected consciously or unconsciously by the player, the latter being primarily motivated by the ludic nature of the game. The reflectivity appears more often than not, therefore, as an added value generated involuntarily by visiting the game. The learning that results is not sought by the players as

\footnotetext{
'Translation by Brian Cleveland.
} 
an end in itself and the game designers (except for designers of serious games) did not intentionally attempt to stimulate it. However, there are persuasive games where the intention is to convince the player of the validity of the thesis and of the values conveyed. Therefore, the creators of these games promote their reflective potential — or, more properly speaking, their persuasive potential — to the detriment of their ludic aspect. In doing so, they orchestrate and direct the power of revelation of the games, which then form part of an authorial logic conforming to the principle of procedural rhetoric.

These rigged games, supported by a persuasive project, include editorial games, and of these editorial games, in the context of this article, we will focus on Every Day the Same Dream (hereinafter, "EDSD").

In the first section of this article we describe EDSD as a game and as a thesis. We then introduce the concept of micro-apparatus of procedural closure of the experiential field (second section), to allow a better understanding of how the game functions as a vehicle for a persuasive message (third section). The following sections relate to the reception of the game. We will thus see how the players provide a narrative through the EDSD sequences they realize (fourth section), what is their interpretative stance regarding this thesis (fifth section) and in what form the phenomenon of reflectivity presents itself (sixth section).

To analyze the strategies of persuasion of EDSD, we have considered it as a thesis game, that is to say a game engaging a thesis, a doctrine, in a manner intended to be univocal. Following Suleiman (1983), we consider that the exposure of the thesis of the game involves the formation of a system of redundancies. Thus, the persuasive message is expressed in the game not only through the elements of the content (visual representations, dialogues of the characters, etc.), but also through the formal elements (rhythm of the soundtrack, the choice of colors, rules of the game, simulation parameters, etc.). It is through the redundancy of the message, of its transmission through various channels, that a thesis is exhibited. In order to reveal the thesis of EDSD, we have reconstructed its system of redundancy. This method has the advantage that the analyst can avoid (as far as is possible, of course) the pitfall of an interpretation that is too strongly tinged with subjectivity.

In order to study the reception of EDSD, we analyzed a corpus of 1048 comments relating to the game and published by the players in the discussion forums Newgrounds (2014) (hereinafter "NG") and Priseztete (2013) (hereinafter "P2T"). Specifically, we selected the set of comments reflecting the EDSD narrative, delivering an interpretation of the thesis, or demonstrating its reflective scope.

\section{DESCRIPTION OF THE EDSD GAME}

In the context of this article, we will examine the editorial game Every Day the Same Dream. According to Bogost, Ferrari \& Schweizer (2010: 6), editorial games are defined as games that convey "an opinion with the goal of persuading players to agree with embedded bias — or at least to consider an issue in a different light". They are "current 
event games with an argument, or those that attempt to persuade their players in some way" (Bogost et al.: 16). EDSD, subtitled "a little art game about alienation and refusal of labour", is a browser game, that is to say, a game the player accesses online through a web browser without installation or download. It features the dull daily routine of an office worker who must complete a series of five actions to put an end to the repetitive and alienating nature of his life and to the logic of productivity in which he operates.

EDSD, by Paolo Pedercini, was designed in six days as part of the Experimental Gameplay Project competition in 2009. Pedercini is a video game developer, artist and professor at Carnegie Mellon University in the field of experimental design of video games. Under the name Molleindustria, he designs editorial games defending social, political or economic thesis. According to Pedercini, "the purpose of an editorial game is not to hold a rigid discourse [...] [but] to create a cloud of connections, to push the player to question themselves" (quoted in Maurin, 2010: non-paginated) (free translation). Molleindustria advocates radicalization and reappropriation of video games. It offers its products as "homeopathic remedies to the idiocy of mainstream entertainment" (Molleindustria, 2012). In a satirical fashion, its games offer a critique of globalization and of the labor market (Oiligarchy, Phone Story, McDonald's Video Game, Tuboflex), of religion (Operation: Pedopriest, Run, Jesus Run!, Faith Fighter), of the military-industrial complex (Unmanned) and of freedom of expression and communication (The Free Culture Game, Leaky World).

The paratext ${ }^{2}$ of the game delivers a clue about the message it carries. The title, "Every Day the Same Dream" suggests repetition of content (the days repeat and appear alike) and of form (alliteration of Same/Dream and Day/ Dream and the assonance of Every/Dream). The subtitle, A game about alienation and refusal of labor, meanwhile, links repetition to alienation and advocates the refusal of labor. The game depicts the daily routine of a worker (the repetition). The five conditions for victory in the game (see the figure below) all relate to the need to break the routine, to be counter-productive by refusing to work and to demonstrate non-conformism: to appear naked at work and get fired (1), take time to pet a cow in a meadow (2) and to catch a leaf that falls off a tree (3), speak to a homeless person (4), and to commit suicide (5), in order to become a new person. When the player enters their cubicle to work, it triggers a rule that returns them to the starting point (a new day begins, just like all the others). If the player works, they are condemned to continuously repeat the same sequences of play. Moreover, the optimal sequence of play to meet these five conditions excludes that the player goes to their office and works. Once the five conditions have been met, the player must live one last day. The game scenes are emptied of human presence and when the player reaches the final scene, they see themselves metaphorically jumping from the top of the office tower where they worked to become a new person, free from the routine, or they see it as their last colleague committing suicide in the wake of the financial disarray of the company as a result of their refusal to participate in its productivity. The interpretations are compatible and support both parts of the message.

\footnotetext{
${ }^{2}$ Paratext: speeches, commentaries and presentations surrounding a work.
} 


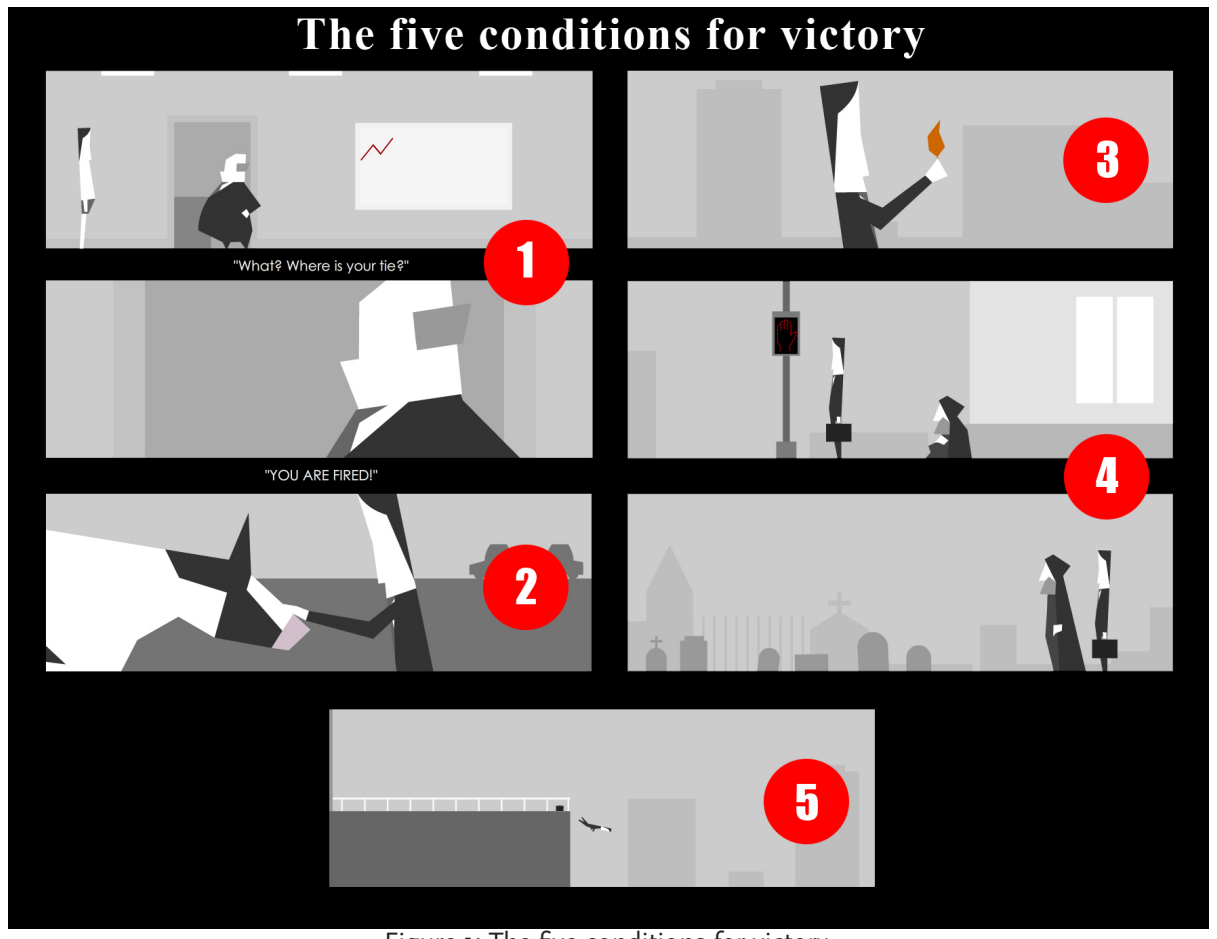

Figure 1: The five conditions for victory.

Editorial games assume the specific characteristics of romans à thèse (thesis novels), which Suleiman (1983: 1) defined as a type of novel which explicitly puts forth "recognized body of doctrine or system of ideas" and which has an "unambiguous dualistic system of values [...] rules of action addressed to the reader [and a] doctrinal intertext" (Suleiman, 1983: 54). Therefore, editorial games could be classified as "à thèse" games or "thesis games." The system of values of EDSD is clearly expressed in the message of the game: "Work and the daily routine are alienating. To break free of this alienation, it is necessary to stop working and break the routine." The game pits alienation against freedom in a binary system (follow the alienating routine or play truant), productivity against the refusal to work leading to the collapse of the economy (when a victory condition is reached the graph showing the profits of the company that employs the main character plunges into the negative), conformity against nonconformity (the character arrives in the office in his underwear, refusing to dress properly in the suit and tie required by the boss), etc. The rule of action concerns the pragmatic dimension of the game. It is revealed by the player in the reading they apply (interpretive discourse) of the narrative discourse and takes the form of an imperative that is addressed to the recipient of the game (Suleiman, 1983). In EDSD, this imperative comes in the form of an incentive to break routine by adopting unexpected behavior, to not conform, and by refusing to be a player in the economy. The doctrinal intertext, finally, points to slogans such as "Never work" by Guy Debord, or to essays such as The Right to Be Lazy by Paul Lafargue, or others on degrowth, simple living, refusal of work, etc.

Beyond these characteristics, it is necessary to examine the strategies used by the designer of EDSD to ensure an effective exposure of its thesis. For this, we developed 
the concept of micro-apparatus of procedural closure of the experiential field ("microdispositif de clôture procédurale du champ expérientiel").

\section{MICRO-APPARATUS OF PROCEDURAL CLOSURE OF THE EXPERIENTIAL FIELD}

The concept of micro-apparatus of procedural closure of the experiential field gives an account of the discursive, semiotic and procedural strategies put in place by the designer of a game to convey a thesis. It is based on a set of concepts: system of redundancy (Suleiman, 1983), quasi world of texts (Ricœur, 2007), apparatus (Foucault, 1980), procedural rhetoric (Bogost, 2008), preferred meaning (Hall, 1980; 1989) and discursive closure (Deetz, 1991).

When we refer to the concept of micro-apparatus, we consider the definition given by Foucault (1980), of

a thoroughly heterogeneous ensemble consisting of discourses, institutions, architectural forms, regulatory decisions, laws, administrative measures, scientific statements, philosophical, moral and philanthropic propositions-in short, the said as much as the unsaid. Such are the elements of the apparatus. The apparatus itself is the system of relations that can be established between these elements (Foucault, 1980: 194).

According to this definition, the apparatuses appear as sets and not interrelated elements; they are networks that bind these elements between them: "[B]etween these elements, whether discursive or non-discursive, there is a sort of interplay of shifts of positions and modifications of function which can also vary very widely". (Foucault, 1980: 195) Foucauldian apparatus is inseparable from the issue of power and strategy, the latter being also present in the military sense of the word. We use this concept because it allows us to think about, on the one hand, the synergy that results from a set of heterogeneous elements (discursive, semiotic and procedural) in interaction with each other and, secondly, the strategic intent behind it. We add the "micro" prefix to the apparatus given that it unfolds on a local scale, that of a work, rather than macro, that of a social project. This implies a stronger control on the persuasive project, since it is the deed of one actor or a small group of actors: the author or authors of the work and its receptors.

The concept of preferred meaning refers to the fact that the meaning of a work here a video game - is "polysemic in its intrinsic nature [and] [i]t is caught in and constituted by the struggle to 'prefer' one among many meanings as the dominant" (Hall, 1989: 47). While the producer of media content encodes a program to give it a unique interpretation, the inherent polysemy of the signs does not guarantee that its reading is consistent with the preferred meaning, as we shall see in the analysis of the reception of EDSD. In the framework of thesis games, the preferred meaning is that which is conveyed by the argument put forward by the designer of the game. It appears as dominant because it is supported by the persuasive strategies of the latter.

The concept of discursive closure (Deetz, 1991) reports on the processes used by an individual in order to silence or eliminate the conflicts and contradictions in a given 
discursive field. In our case, the principle of closure demonstrates the persuasive strategies present in a game in order to identify the preferred meaning it puts forward that is intended to be an unambiguous thesis, or monosemic. "Confine" and not "impose": indeed, the closure is not a frontal act of persuasion, but a more subtle act of blurring certain interpretations, to guide the receiver of a message which has the appearance of virgin and abundant territory and which is, in reality, an insidiously marked trail. While certain closure strategies are discursive (thinking specifically of the paratexts of the title and subtitle of EDSD, to the interviews given by Perdercini about his game, etc.), or more broadly semiotic (images, music), others relate to procedural rhetoric.

"Procedural" is considered to be the behaviors generated by a processor using rules (Murray, 2004). According to Bogost (2008), «procedurality» is a

set of constraints that create possibility spaces, which can be explored through play [...] To write procedurally, one authors code that enforces rules to generate some kind of representation, rather than authoring the representation itself. Procedural systems generate behaviors based on rulebased models; they are machines capable of producing many outcomes, each conforming to the same overall guidelines (Bogost, 2008: 122).

The term "procedural rhetoric" refers to the expression of persuasive messages and abstract ideas articulated in a procedural form, the demonstration being made through the use of simulation. The idea of procedural closure that we put forward refers to the strategies intended to include a message of a persuasive nature - a thesis - in the formal structure of the game ${ }^{3}$. Therein resides the insidious signs of the meaning of a message that is truly videoludic.

The quasi world of texts concept (Ricoeur, 2007) is based on the dynamic relationship, in the grasping of a text, of the explication and of the understanding. The sense that the philosopher gives to the understanding is based on reflective philosophy. Reflection is the search for transparency of the subject itself. The reflective tradition involves introspection, whereas for Ricoeur, "all self-knowledge is mediated through signs and works" (Ricoeur, 2007: 61). Therefore, the human experience appears to be essentially linguistic. With respect to the explanation, the philosopher assigns to hermeneutics the task of studying the work of the text, or the internal dynamics responsible for the structuring of the work (to explain) and the ability of the work to produce a quasi world of texts into which the reader can project themselves, which they can inhabit and which opens to a self-knowledge (understanding). This task is the interpretation.

The reception of a text, based on the work of Hall (1980), demonstrates the competing interpretations preferred by the author. A video game offers the player an experiential field, a simulated world in which they experience a range of situations and emotions, and grasp a set of signs, symbols and discourses that are not part of their daily

\footnotetext{
3 The formal structure produces, consumes and organizes verbal signs and forms of expression, similarly to how it produces sequences of events when the player interacts with it. It is a set of rules and parameters that govern the actions of the players and simulate the game world, giving it consistency and playability
} 
life. Meanwhile, the player, in grasping the quasi world of texts, engages in a reflective act of self-knowledge (we will add "and of understanding of the world of the player, of the society within which they are integrating themselves"). This act is prompted by the experiences gained when interacting with the game. The experiences in question are drawn from a set of possibilities belonging to the aforementioned experiential field. Within the concept of micro-apparatus of procedural closure of the experiential field, we understand that some possible experiences are emphasized at the expense of others through the procedural closure. These possibilities are not emphasized by chance; they are placed there to serve the thesis of the game designer. The quasi world of texts is largely the result of the formal structure of the game, of its procedures. When this marks out the experiential field, the reflective act of the player appears limited as a consequence.

To complete our definition of the micro-apparatus of procedural closure of the experiential field, we must clarify the reference to the system of redundancy of Suleiman (1983). According to her, indeed, a thesis novel (or, in our case, a thesis game), carries an unambiguous doctrine. To achieve its ends, it expresses them using the principle of redundancy. Thus, to avoid entropy in its meaning, the message is repeated through different channels, coming in many forms. In a thesis game, for example, a doctrine can be expressed procedurally, but also through character dialogues, architectural elements, symbols, icons, etc.

\section{The PERSUASIVE STRATEgIES MOBILIZED IN EDSD}

In terms of content, the alienation of the worker and routine are expressed by the images and music of the game. With regard to the alienation, we can see the anonymity of an office worker without any specific features to distinguish him from other individuals, the row of identical cubicles in which colleagues are enclosed and who engage in a mechanical pantomime, and the morose look of the game graphics in washed out shades of gray. In terms of routine, we note the synchronization of the actions performed by the office workers and the looped music that runs at a constant pace.

With respect to the formal structure, the EDSD thesis is expressed through the goals that must be achieved to win. The routine is represented by the invariant sequence of game scenes, which repeats the daily cycle of the main character: get up, go to work, work, repeat. Game progression is zero, the player being systematically returned to square one. The player actually only progresses when the objectives are achieved - when the rules are followed. The cycle is broken and the game evolves; new segments are presented (petting a cow, following a homeless person to a cemetery, etc.). In summary, routine $=$ defeat, breaking the routine $=$ victory. The anti-capitalist impulse of the game is expressed in the same way, since by working the character delays the eventual victory, which occurs only when the business enters bankruptcy.

The demonstration is eloquent insofar as it forces the player to experience routine and alienation, and only the rejection of this experience and adherence to the lifestyle suggested by the game allows the player to escape a cycle worthy of Sisyphus. Therefore, the experiential field, while not offering a compulsory path, strongly suggests the 
adoption of a predetermined sequence of actions, which is accompanied by one kind of experience at the expense of another.

Uncovering the victory conditions of the game means that the player is in "problem solving" mode and this infers taking actions that ensure the progression of the game and learning which actions have no effect. This involves cognitive processes whose mobilization probably forms the deepest level of the statement of the thesis with regard to the system of redundancy. In order to win the game, the player must avoid three major pitfalls which constitute the many forms of routinization of thought: the significance of behavioral scripts, functional fixedness and mental ruts.

\section{BEHAVIORAL SCRIPTS}

The game mobilizes specific behavioral scripts (Abbott et al., 1985) (Bower et al., 1979) (Schank \& Abelson, 1977) through which the player is encouraged to enter into the routine of the game without being able to discern the elements necessary to achieve the victory conditions. A script is a knowledge scheme represented in memory and consists of information related to an episode or situation (e.g. going to a restaurant) that allows us to understand and memorize it. For a given event, it contains the elements that constitute it and the order in which these occur, from a general point of view. The routine invoked by EDSD calls on such scripts: "wake up in the morning" and "go to the office to work." If you ask a hundred subjects to state the usual procedure relating to these two events, some of their responses are likely to overlap. Thus, it is expected that the items "get out of bed" and "get dressed" figure in the procedures involved in the script "wake up in the morning." However, it is likely that responses of "walk past the office without stopping", "take the emergency exit" and "jump off the building" do not figure in the script "go to office to work." Therefore, a player who does not know the goals of the game will tend to rely on scripts that they have in memory and with which they are familiar and are understood, with the aid of the context in which their character finds itself and the responses given by the other characters, that they must get ready and go to work. These scripts act as guides to the action. However, relying on the suggested scripts makes it impossible to achieve victory, since the player is expected to break the routine by adopting unaccustomed behaviors.

\section{FUNCTIONAL FIXEDNESS AND MENTAL RUTS}

The game also counts on, in order to thwart the player, the overactivity of top-down or theory driven processing. Top-down processing refers to the fact that cognitive processes are guided by concepts, perceptions, expectations and mnemonic activity, as opposed to bottom-up or data driven processing, in which these processes are guided by information arising from the stimuli. With respect to problem solving, functional fixedness and mental ruts constitute two phenomena of overactivation of top-down processing.

Functional fixedness (Duncker, 1945) (German \& Barrett, 2005) (McCaffrey, 2012) refers to the lack of innovation of individuals in strategies of problem solving and more 
specifically in the use of tools that are perceived only in the light of their common usage. In $E D S D$, functional fixedness prevents the player from imagining how some objects might lead to accomplishing two victory conditions. The first object is the car. As part of the script "go to work", the car is immediately seen as a way to get from home to the workplace. Its use is primarily related to work. However, when the player considers it as a recreational tool and stops in the middle of the usual route, they can enter a meadow and pet a cow, creating an emotional connection that they are denied by the other characters (victory condition $\mathrm{n}^{\circ} 2$ ).

Mental ruts (Smith, 1996), in turn, refers to the habit of solving a new problem by applying strategies that have proven successful in the past, but are inappropriate or unnecessarily complicated in the current situation. In EDSD, the player tends to move the character from left to right, which reveals two patterns: the first relates to the running of text from left to right for the Western reader. The second is the habit of moving a character from left to right in a platform game in order to reach a destination and to advance in the game. To meet the fourth condition of victory, the player must go to the left of the parking lot scene rather than the right, which leads to a new scene in which they are able to talk to a homeless person. The strategy whereby the player progresses by systematically moving to the right is inoperative here, to the extent that this departure from the norm is an important goal.

All three of functional fixedness, use of scripts and mental ruts divert the player away from victory. Their presence is an illustration, in terms of the formal structure and cognitive processes it calls upon, of the deleterious routine that the player must escape at all costs. Not only do these cognitive obstacles make the game more difficult, but are also a comment on the meta-ludic routine which repeats the conveyed message exposed by the content elements of EDSD.

\section{The EDSD NARRATIVE}

While the validity of the thesis of Pedercini is demonstrated through the ludic mechanisms involving problem solving strategies, nothing has been said about the narrative. But for the interactions between the player and the formal structure of the game to be meaningful, they must be arranged in the form of a narrative.

When we analyzed the 1048 comments of our corpus, we found that the actions taken by the players - the trajectories followed in the experiential field of play - were understood not only in terms of their relevance to the achievement of victory, or in other words in procedural terms, but also in terms of the narrative that could be formulated from their sequence. Now, on the one hand, while the order of achievement of the five victory conditions is irrelevant in the eyes of the formal structure, the different narratives generated according to the sequence order and in consideration of the game segments and actions that the player takes, are relevant.

According to Ricoeur (1983), the narrative is a way of ordering and understanding the experience that, without its help, is fundamentally discordant for whoever lives it. The 
hermeneutic value of video games lies in the ability to create experiences that will then form a narrative that is relevant to the life of the player. The corpus of comments we analyzed reveals these narratives. We have seen that the narratives changed according to the order of fulfilling the sequence of the game, as well as the interpretation of the meaning of these sequences. This comment, from Nana Pancake, reflects this: "The routine of the worker is very depressing. I say, leave the suicide until the end, it makes more sense. It's as if he came back and watched himself jump." (P2T, 12/07/2010).

The following narrative, from FluidMotion, illustrates the balance between the achievement of the victory conditions and their meaning in accordance with the emphasis of the thesis by the micro-apparatus of its author:

5 days ago $\mathrm{i}$ got ready for work got on the elevator a strange lady said $\mathrm{i}$ needed to 5 steps to become a new person...well that really scared me so $\mathrm{i}$ just went to work that day [...] The day after that the same lady in the elevator told me I had to take five steps for a new life. It made me think of how boring my life was so i decided to skip work today [...] Well after i went to work and i saw a cow. i decided to come out of my car and touched it, it felt like this is something i needed to do to make a better life (NG, 19/08/2010).

Each step, in fact, is rooted in the thesis during its narration. Thus, the fact that the counter of the elevator lady is locked at five is related to the boredom of a dull life. Petting a cow in a field raises the need for a change in the narrator's life, etc.

That being said, nothing prevents the players from deriding, hiding (voluntarily or not) or questioning the thesis of the game. This is illustrated by the following narrative by pikachudance, who reinterprets the last day of the character with a little caustic humor: "where did everyone go? the company I work for seemed to have gone broke, my wife left me for going to work with no pants on and some guy stole my suiside spot. That jerk.he could have said hi first" (NG, 11/07/2011).

The following two comments show that the same segment may be the subject of different narratives (and interpretations). Lightmare wrote: "once out of the building, you can go left where a bum takes you into a graveyard and kills you" (P2T, 22/12/2009). To which Will retorted:

He doesn't kill you, he takes you somewhere quiet (a cemetery) to get you out of your everyday routine. You lose a day of your precious time for each step and this lowers the productivity curve of the company, removing you from your role as a well-oiled cog to become a person who does not necessarily have a purpose or "mission", but benefits just a little from what he has left ...

It's very depressing but real ... A thought for all of you who slog in the office. Me outside, I'm cold in winter but for the remaining nine months it's great !! (P2T, 29/01/2010).

While the second narrative is consistent with the preferred meaning of the game, the first is not pertinent, since it does not lead its author to express a contradictory 
interpretation, since he adds: "In fact, I think this game denounces the monotony of days that are all the same, as it is gray and the progress is so set that you can guess the outcome" (P2T, 22-12-2009).

\title{
INTERPRETATIVE POSTURES OF THE EDSD THESIS
}

After analysis, it is possible to divide interpretations of the thesis by the players into five classes, according to whether the communication of the thesis is a success or a failure, and depending on whether the player adheres to the thesis, rejects it or reserves judgment on it. The cases for which the communication is successful can also be divided into two, depending on whether or not the player has discovered the two main dimensions of the thesis. Indeed, the latter divides into: rejection of routine, on the one hand, and, on the other, rejection of productivity and of labor. However, some players have only realized one or the other of the dimensions of the thesis.

Success / adhesion: the players understand the thesis expressed in the game and adhere to it. This is the case of Sirodil who wrote: "Well it's a pretty moral to say 'Don't be someone else's tool'" (P2T, 31-12-2009). The latter, however, reveals only one dimension of the thesis, that is to say, the rejection of labor, omitting the dimension concerning the rejection of routine. This is also the case of carlylynnmorgan, according to who the moral is "[r]eally deep and shows how miserable life is to a corporate worker who does the same thing every single day. It's an inspiration" (NG, 01/07/2010).

Beyond the question of the adhesion of the player, the following comment reflects the polysemy of EDSD, but also of the gentle strategy employed by the author through the micro-apparatus of closure, a strategy that opposes a frontal exposure of the thesis. Asgard314 interprets the game in two ways that enrich the video game text and appear compatible:

\begin{abstract}
Was it all purgatory and he finally saw his death in the last day? Was it all a dream of how his life was caught in a routine? I don't know, though I don't really want to know. The mystery in itself is the thing that draws one into this world along with the parallels with life's repetitive nature (NG, 05/12/2010).
\end{abstract}

Success / rejection: the players understand the thesis as expressed in the game and totally reject it. This is the case of Earthquake21, who understands the negative connotation attached to a life of boredom in the game, but for his part, considers the routine presented to him as enviable: “i just didn't see a message or meaning, perhaps someone can explain it to me. I think its about having a dull life, but I'm actually jealous and wish i had a life like the character. A wife, a job, a purpose what more could you want?" (NG, $03 / 07 / 2010)$. This is also the case of Sigma34561 who considers white collar Caucasian routine as an enviable status in comparison to those experiencing unemployment, famine and dictatorship:

The message of the game? It sucks to be a white collar white guy. I'm sure the unemployed people, the starving people of third world countries, and 
those living under tyrannical governments around the world are glad they aren't boring white people (NG, 01/07/2010).

Success / No opinion: the players understand the thesis as expressed in the game and did not state an opinion on the subject. Here IllusionOfChaos puts forward the thesis of the routine without giving an opinion and without regard to the productivity / labour dimension. This is a partial success, as one dimension of the thesis is exposed:

As for the message itself: my interpretation of it was that it had two parts. The first part is that sometimes doing the little things differently can make life more enjoyable. The second part is that being different forces you to walk a lonely path (indicated by the ending scene where everybody is gone). I didn't quite understand the very ending [...] Perhaps that's witnessing his former boring life end? (NG, 02/07/2010)

Same thing for SandwichDeLuxe who writes : "I think, what the author is trying to say is that you have the right and possibility to fight for your happiness, by breaking down this vicious circle" (NG, 02/07/2010).

Failure / No opinion: the players attach a different thesis to the game than the one promoted. The transmission of the thesis results in a failure and the player cannot therefore adhere to or reject it (although they may or may not adhere to a competing thesis). We found the two following cases:

a. The players recognize the thesis of the game as one possible interpretation among various, but they minimize it and put forward an alternative interpretation which they consider more consistent with the persuasive project of the game or even deeper. The interpretation of YazoProductions is an example of such:

It could be showing how suicide is kind of a selfish thing. Assuming you save killing yourself for the last "dream", then when you wake up you realize the little things in your "boring life" disappear, like your wife, the woman in the elevator, your boss, the workers... You never really had much thought for them before, but once they were gone, your day felt incomplete. It could just be a poke at how our lives are boring and repetitive, but I feel it has more meaning than that. It could show how our insatiable craving for something more or different can get the better of us, and make us lose everything we had to begin with (NG, 13/05/2013).

b. The players do not recognize the thesis of the game and put forward a different interpretation. We take the example of TomoyaAyame who commented on the game in the following manner: "it makes me feel sad that there's just no escape" (NG, 19/08/2010). Thus, the player has experienced the routine offered by EDSD, but seems not to have encountered the sequences to break it (the five victory conditions). This communication failure illustrates the problem of any procedural rhetoric: the receiver must engage with the game in depth to uncover the thesis that it proposes. The interpretation of Lightmare shows the problematicity related to this level of commitment, "In fact, I think this 
game denounces the monotony of days that are all the same [...] I don't actually know if something changes in the long run, I abandoned it after getting up 8 times ..." (P2T, $22 / 12 / 2009)$. The player failed to attain all the conditions of victory and to understand the full demonstration of the thesis. Their narrative of the game reflects not only the incompleteness of the transmission of the thesis, but also the inability of the player to discriminate between relevant and irrelevant segments of the game:

You get up, turn off the alarm [an action that has no effect on the game], the TV [ditto], and you leave for work. If you pay attention, the lady in the elevator tells you that in 5 steps you will be a new man, then in 4,3 ... But I don't know what to do to make her say something else.

However, once you're out of the building, you can go left where a bum takes you into a cemetery and kills you [misinterpretation of the meaning of the action of the homeless person]. [...] (Unimportant detail: When you walk down the street and you see a tree with one leaf, if you come back to it right afterwards the leaf has disappeared [victory condition interpreted by the player as having no effect on the game] [...] (Unimportant detail 2: as the days go on, the red curve on the table in the corridor advance [ditto] (P2T, 22/12/2009).

On the one hand, the discovery of the thesis involves some minimal videogame skills (use of game controls, the ability to solve puzzles, etc.) rather than just a case of simply reading or interpreting a text. On the other hand, it raises questions about the target player of the game. Indeed, to uncover the thesis, the player must be able to achieve different victory conditions. However, this involves cognitive strategies and a sense of exploration that appear to us inconsistent with the adoption of routine behavior. Therefore, the game preaches to the converted and the perlocutionary effect of the message conveyed is inoperative.

\section{The REFLECTIVE VALUE OF EDSD}

Beyond the different interpretations and narratives, we retain the value of EDSD as a quasi world of texts. We have seen how this world has been configured, closed by the micro-apparatus of Pedercini (explanation). micro-apparatus of Pedercini (explanation). We shall now examine how the power of revelation translates in a concrete way on the self (on life, values, mobilized cognitive processes) and on society (reflections on the video game medium, on the contemporary world, its culture, history, etc.) (understanding) with the aid of the reflective comments from the players.

Reflectivity of the game takes various forms. We uncovered five in the analysis of our corpus: meta-cognitive, social, meta-ludic, self-reflectivity and metatextual reflectivity.

Meta-cognitive reflectivity: EDSD, as we have seen, repeats its thesis by placing cognitive obstacles in the way of the players. These obstacles are perceived as such by some, who apply a meta-cognitive feedback to their gaming experience, like Bakedpie: "At first I was doing his [the character of EDSD] normal routine, but then I slowly realized that I had to think OUTSIDE the box" (NG, 30/06/2010). 
The case of slyc demonstrates, however, a questioning of their values. The search for perfection through repetition, previously seen as a positive value, is reassessed negatively as it proves harmful to anyone seeking happiness:

Here I thought that doing the same thing EVERY TIME, EVERY DAY made you better at something... it will, but at what cost? Happiness is that cost $[\ldots]$ Its the same repetitive thing over and over again. [...] And to that factor, I thank you [Pedercini] for making me realize our mistakes (NG, 09/07/2010).

If Bakedpie translated the resolution strategy of the problem posed by EDSD in cognitive terms ("thinking outside the box"), others translated it along the lines of the thesis in terms of freedom of spirit and individuality, qualities that refer to the relationship of the individual with society. Sargeog6 thus described EDSD as "a wonderful parabole of the free spirit and a sense of individualism" (NG, 21/12/2010).

Reflectivity on the social world: the power of revelation of the game creates reflections on the contemporary social world of the player. Jesuispotato, for example, links the condition of the main character of the game to that of the white man, whose culture seems to exclude community values in general and family in particular, which give meaning to life:

Man this guy has a boring life, seriously i always hear about people living lives like these but $i$ think thats only for white people $>$.> i mean where is the family? friends? the music? the bbqs? Where is all of this? I think you will find that it is mainly white people that live far away from their familes 0.0 any other culture the person always lives close to their family (NG, 30/06/2010).

The remainder of the commentary shows that reflectivity does not apply exclusively to the contemporary world, but also to the socio-historical reasons for his position: "Not racism just something that has been part since the early 1900 shen urban cities began to populate" (Ibid.).

The following comment from Nilithius is also intended to be a critical reflection on contemporary society by stating that EDSD is "a good protest against making people robots under the society and such" (NG, 05/06/2010).

For elephant27, finally, EDSD is an opportunity to illustrate a real social phenomenon in a video gaming manner: "I read an article somewhere that said how most people who go suicide are people who have desk jobs. People like the guy in this game" (NG, 30/06/2010).

Meta-textual reflectivity: reflectivity comes in the form of a meta-textuality when the player has the opportunity to relocate the game into a larger pool of texts, the latter then acting as intertexts ${ }^{4}$. For example, ekura relocates EDSD into the realm of Western culture: Greek mythology and existentialist philosophy (the myth of Sisyphus and its reading by Albert Camus):

\footnotetext{
${ }^{4}$ What is an intertext? On this subject, Julia Kristeva (1980) writes that "any text is constructed as a mosaic of quotations; any text is the absorption and transformation of another" (p. 66). This is called "intertextuality" ("the transposition of a system of signs into another system of signs", p. 15) and the texts cited constitute "intertexts".
} 
The ending [of EDSD] reminds me of The Myth of Sisyphus. Within the loop of his boring daily life there is another loop in which he is continuously trying to break free, the guy he watches jump off at the end is himself in a later iteration of the loop signifying he will never truly be free. (NG, 01/07/2010)

Caufield relates the intention of the game to the literature of Kafka and popular culture: "short take on Kafka. It's sort of like a combination of Groundhog Day and Vanilla Sky, but filtered through the bleak lens of existentialism." (NG, 29/06/2010). Finally, Infamus15 (NG, 02/07/2010) presents a selection of quotes from politicians and famous actors on conformity.

Self-reflectivity: the following comments are probably those that best illustrate the practical relevance of the action rule proposed by EDSD as a game thesis. THhappy wrote "Hell I may quit my shitty job" (NG, 06/07/2010) and DANTE30101990 : "I receive the important message from the game, and everyday in my entire life, try to fight a better place for myself." (NG, 20/07/2010). If the message received by THhappy and DANTE30101990 serves as a call for a change of lifestyle, it acts as a warning to Thecatofnimes ("Hope I don't end up like that guy [the character of the game]", NG, 13/02/2012), D)827 ("perfect game. it makes me want to do good in school so i dont end up like that guy", NG, 30/06/2010), and raises regrets for WingsofVengeance who, by their own admission, was unable to avoid the pitfalls of routine during their life ("describing my life at a desk job. Kids, follow your drems. You run with the crowd and you will be just a number", NG, 30/06/2010). The latter also takes up the baton of the game thesis and promotes the same rule of action by advising young people to follow their aspirations.

Meta-ludic reflectivity: the meta-ludic reflectivity reveals cases where players take a critical look not at their own existence or their place in the contemporary world, but at the characteristics of the game as a medium or instrument of communication. The following commentary, posted by runawayBro, belongs to the first case since it calls into question the appropriateness of the video game medium to express the EDSD message:

I think it would have honestly functioned better as a movie, since holding right to inch forward through endless screens is tedious enough to seriously discourage the experimentation that is the game's big feature. [...] your message is actively detrimental to the medium through which you're expressing it (NG, 04/05/2011).

This is also the case of the comment by Colonel Kickass who highlights the suitability of the cyclical nature of video games and the monotony of life: "I do enjoy the authors use of the cyclical manner of games to parallel the monotony of life" (NG, 30/12/2010).

Finally, the case of yodiz111 can be placed halfway between personal reflection and meta-ludic reflection insofar as he binds together the conformist behaviors of the player in his daily life to the gaming habits which are themselves conformist, implying that in exercising this parallel it is precisely how the game expresses its message:

Its kind of mind opening how I ran threw the whole regular day like twice before even thinking about making him do something out of the norm. I 
still follow my stupid norms in a dumb game on the internet. Which is a part of the message I guess (21/08/2010).

\section{Conclusion}

Every Day the Same Dream is a thesis game and comes structurally in the form of a micro-apparatus of closure of the experiential field. As such, it presents a normative perspective on contemporary society as well as an incentive for the player to change. We have seen, however, by analyzing the reception of EDSD, that the strategies of persuasion prove only partially effective, despite the redundancy of the message and the closure of the experiential field. This can be explained by the establishment of an apparatus which comes, Foucault (1980) tells us, from a phenomenon of "strategic elaboration", or in other words, an unforeseen effect from the establishment of the apparatus, that the philosopher illustrates in Discipline and Punish: The Birth of the Prison, by the constitution of a delinquent milieu when creating the prison apparatus from the end of the eighteenth century. This strategic elaboration demonstrates the fallibility of any game in its aim to express a univocal thesis, - voluntarily or involuntarily, consciously or unconsciously —, polysemy will always be the final result. Thus, some players can boast of beating EDSD in less than half an hour or having optimized the sequence to accomplish the victory conditions, the exercise demonstrating a search for productivity and efficiency that can be considered heretical in the eyes of the thesis, but is permitted or even encouraged by the gaming culture (thinking particularly of speedrun) and by the formal structure.

It is paradoxical that EDSD comes in the form of a thesis game. Indeed, the message it promotes opposes conformism and the rigidity of a daily routine. Yet it is itself rigidly expressed through a perspective (and a field of possibilities), that while not unique is at least highly circumscribed. But the paradox dissolves in the plurality of the reception: the game reappears as a free and unpredictable space capable of subverting any unambiguous doctrine such as it is. This is, ultimately, the meta-ludic commentary that EDSD makes on itself.

\section{REFERENCES}

Abbott, V., Black, J. B. \& Smith, E. E. (1985) “The representation of scripts in memory", Journal of Memory and Language, 24: 179-199.

Bogost, I. (2008) "The Rhetoric of Video Games" in Salen, K. (ed.) (2008) The Ecology of Games: Connecting Youth, Games, and Learning, Cambridge: The MIT Press, pp. 117-139.

Bogost, I., Ferrari, S. \& Schweizer, B. (2010) Newsgames: Journalism at Play, Cambridge: The MIT Press.

Bower, G. H, Black, J. B. \& Turner T. J. (1979) "Scripts in Memory for Texts", Cognitive Psychology, 11: 177-220.

Brougère, G. (2002) "Jeu et Loisir comme Espaces d'Apprentissages Informels", Education et Sociétés, 10: 5-20. 
Deetz, S. A. (1991) "Systematically Distorted Communication and Discursive Closure" in Democracy in an Age of Corporate Colonization: Developments in Communication and the Politics of Everyday Life, New York: State University of New York Press, pp. 177-198.

Duncker, K. (1945) “On Problem Solving”, Psychological Monographs, 58 (5): 1-113.

Duret, C. (2014) "Strategies and Tactics in Digital Role-Playing Games: Persuasion and Social Negotiation of the Natural Order Thesis in Second Life's Gorean Community" in D. Ruggiero (ed.) Cases on Societal Effects of Persuasive Games, Hershey: IGI Global Publishing, pp. 250-269.

Foucault, M. (1980) "The Confession of the Flesh" in C. Gordon (ed.) Power/Knowledge Selected Interviews and Other Writings, Warrington: Colin Gordon-Farleigh, pp. 194-228.

Genette, G. (1987) Seuils. Paris:Seuil.

German, T. P. \& Barrett, H. C. (2005) “Functional fixedness in a technologically sparse culture”, Psychological Science, $16(1): 1-5$.

Hall, S. (1980) "Encoding/decoding” in S. Hall, D. Hobson, A. Love \& P. Willis (eds.) Culture, Media, Language, London: Hutchinson, pp. 128-138.

Hall, S. (1989) “Ideology and communication theory” in B. Dervin, L. Grossberg, B. O'Keefe \& E. Wartella (eds.) Rethinking communication I: Paradigm dialogues, Newbury Park, Sage, pp. 40-52.

Kristeva, J. (1980) Desire in Language, Oxford: Basil Blackwell Ltd.

Maurin, F. (2010) “Jeu Vidéo: ‘Je Perds donc Je Pense’”, Le Monde, Retrieved October 6, 2014, from http:// www.lemonde.fr/actualite-medias/article/2010/07/15/jeu-video-je-perds-donc-je-pense-seriousgames-2-5_1385386_3236.html

Molleindustria. (2012) "About", Retrieved October 6, 2014, from http://www.molleindustria.org/blog/about

McCaffrey, T. (2012) "Innovation Relies on the Obscure: A Key to Overcoming the Classic Functional Fixedness Problem", Psychological Science, 23 (3): 215-218.

Murray, J. (2004) "From Game-Story to Cyberdrama", Retrieved October 6, 2014, from http://www.yorku.ca/ caitlin/futurecinemas/resources/coursepack/wardripchapı.pdf,

Newgrounds. (2014) "Every day the same dream", Retrieved October 6, 2014, from http://www.newgrounds. $\mathrm{com} /$ portal/view/540741

Prise2tete. (2013) "Every day the same dream", Retrieved October 6, 2014, from http://www.prise2tete.fr/ forum/viewtopic.php?id=5495

Ricoeur, P. (1983) Temps et récit, Tome 1, Paris: Seuil.

Ricoeur, P. (2007) From Text to Action: Essays in Hermeneutics, II, Evanston: Northwestern University Press.

Schank, R. C. \& R. P. Abelson. (1977) Scripts, Plans, Goals and Understanding: an Inquiry into Human Knowledge Structures, Hillsdale: L. Erlbaum.

Smith, S. M. (1996) "Getting into and out of mental ruts: A theory of fixation, incubation, and insight" in R. J. Sternberg \& J. E. Davidson (eds.) The nature of insight, Cambridge: The MIT Press, pp. 229-251.

Suleiman, S. R. (1983) Le Roman à Thèse ou L'autorité Fictive, Paris: Presses Universitaires de France. 
Trémel, L. (2002) “Les Jeux de Rôles, les Jeux Vidéo et le Cinéma: Pratiques Sociales, Reproblématisation de Savoirs et Critique, Education et Sociétés, 10: 45-56.

\section{LUDOGRAPHY}

Molleindustria (2003), Tuboflex@

Molleindustria (2006), McDonald's Video Game@

Molleindustria (2007), Operation: Pedopriest@

Molleindustria (2008), Faith Fighter@

Molleindustria (2008), Oiligarchy@

Molleindustria (2008), The Free Culture Game@

Molleindustria (2009), Every Day the Same Dream@

Molleindustria (2010), Leaky World: a Playable Theory@

Molleindustria (2010), Run, Jesus Run!@

Molleindustria (2011), Phone Story@

Molleindustria (2012), Unmanned@

\section{ACKNOWLEDGEMENTS AND FUNDING}

This research was supported by the Social Sciences and Humanities Research Council of Canada and the Fonds Québécois de la Recherche sur la Société et la Culture.

\section{Bio NOTE}

Christophe Duret has a Master of Arts in Communication at Université de Sherbrooke (Canada), where he is currently a graduate student in French Studies. His research focuses on online role-playing games in both sociocritical and hermeneutical ways. In particular, he has interest for the processes of videogame adaptation from novels and in the strategies and tactics used by players in order to understand how they challenge or defend a specific doctrine in their role-play.

E-mail: christophe.duret@hotmail.com

Université de Sherbrooke 2500 boul. de l'Université, Sherbrooke, Canada

* Submitted: 30-11-2014

* Accepted: 15-3-2015 